\title{
A PROPOSED PERFORMANCE BASED APPROACH FOR LIFE CYCLE ASSESSMENT OF REINFORCED BLENDED CEMENT CONCRETE
}

\author{
Hisham Hafez $^{1 *}$, Wai Ming Cheung ${ }^{1}$, Brabha Nagaratnam ${ }^{1}$, Rawaz Kurda ${ }^{2}$ \\ ${ }^{1}$ Department of Mechanical and Construction Engineering. University of \\ Northumbria. Newcastle upon Tyne, NE1 8ST. \\ ${ }^{2}$ CERIS, Civil Engineering, Architecture and Georresources Department, Instituto \\ Superior Técnico, Universidade de Lisboa, Av. Rovisco Pais, 1049-001 Lisbon, \\ Portugal
}

*Corresponding author. Tel.: +44 7493280699

E-mail address: hisham.hafez@northumbria.ac.uk

\begin{abstract}
The use of supplementary cementitious materials (e.g. fly ash and ground granulated blast furnace slag) as a partial replacement of ordinary Portland cement (OPC) in blended cement (BC) concrete has been established in recent years. However, an optimum mix design of $\mathrm{BC}$ concrete should not only achieve the targeted mechanical properties but also aim at minimizing the cost as well as environmental impacts. The first step towards an accurate estimate of BC concrete's environmental impacts is to define an indicative functional unit. Unfortunately, most of the research that uses life cycle assessment (LCA) to compare OPC and BC concrete, selects a simple functional unit without taking into consideration the difference in mechanical properties and durability characteristics. Although several efforts were found integrating the durability characteristics in the environmental impact assessment over the whole life cycle, no consensus was found. In this study, a novel approach to quantifying the environmental impact of $\mathrm{BC}$ concrete compared to OPC concrete as a part of a decision making process on the type and mixing proportions of concrete to minimize its environmental impact. Using LCA, the method proposes that performance based parameters are defined: a targeted compressive strength and service life. Predictions should be made of these parameters based on generic user-input data like type of BC, water/binder ratios, binder content and OPC replacement rates. The comparative environmental impact is then quantified accordingly. It is believed that this novel approach allows the user to accurately select and proportion a blended cement concrete mix with the objective of minimizing its environmental impact.
\end{abstract}

\section{ABBREVIATIONS}

$\mathrm{BC}$ - Blended Cement; $\mathrm{CC}$ - Concrete Cover; $\mathrm{CO}_{2}$ - Carbon Dioxide; $\mathrm{CS}_{\mathrm{p}}$ - Predicted Compressive Strength; $\mathrm{CS}_{\mathrm{t}}$ - Targeted Compressive Strength; EC - Exposure Conditions; FA - Fly Ash; FU - Functional Unit; GDP - Gross Domestic Product; GGBS - Ground Granulated Blastfurnace Slag; LCA - Life Cycle Assessment; OPC Ordinary Portland Cement; SCM - Supplementary Cementitious Materials; SCp Predicted Sequestered Cabron; SLt - Targeted Service Life; $S_{L} C_{p}$ - Predicted Service 
Life against Carbonation; $\mathrm{SLCP}_{\mathrm{p}}$ - Predicted Service Life against Chloride Penetration; $\mathrm{SL}_{\mathrm{p}}$ - Predicted Service Life.

\section{INTRODUCTION}

Due to its inherent strength and durability properties, concrete is the second most used substance on Earth after water (Serres et al, 2015). Thus, it is responsible for more than $7 \%$ of the $\mathrm{CO}_{2}$ global emissions, which is largely attributed to the Ordinary Portland Cement's (OPC) production ( $>5$ billion tons annually) (Colangelo et al., 2018). Therefore, most of the recent studies follow the 2015 Paris climate conference guidelines, namely reducing the clinker use in concrete to decrease its environmental impact (Vinuales et al., 2017). Among several options, partially replacing OPC with recycled pozzolanic material, i.e. fly ash (FA) and ground granulated blast furnace slag (GGBS) has been the most common (Wang et al., 2017). Since, FA and GGBs are considered by-product materials from coal combustion and iron production processes respectively, they carry minimal environmental burden, relatively to OPC (Seto et al., 2015). For example, the embodied emissions of concrete increased up to $30 \%$ and $60 \%$ with incorporation of $35 \%$ and $70 \%$ of FA and GGBS, respectively (Tait and Cheung, 2016).

Life cycle assessment (LCA) is the most widely accepted tool to assess and compare the environmental impact of conventional and non-conventional concrete mixes, either from "cradle-to-gate" or "cradle-to-grave" (Knoeri et al., 2013). However, the scope of most of the previous studies (Colangelo et al., 2018; Tait and Cheung, 2016) related to the LCA of concrete (e.g. FA concrete) is assessed from "cradle-to-gate" approach. In other words, they only focus on the environmental impact of the materials until the production stage. Therefore, the results in the choice of a functional units (FU) that disregards the "use" phase in the life cycle of concrete resulting in an inaccurate estimate of its total environmental burden as argued by De Schepper et al. (2016). A FU is the parameter responsible for adjusting the quantification of the environmental impact between the products in an LCA (Dobbelaere et al., 2016).

\section{REVIEW OF LIFE CYCLE ASSESSMENT FUNCTIONAL UNITS}

Most of the FU found in the literature that uses to assess the environmental impact of blended cement (BC) concrete and OPC concrete can be classified into the following four main categories.

\subsection{Simple Functional Units}

These are mass or volume based FU that compares a simple unit $\left(1 \mathrm{~kg}\right.$ or $\left.1 \mathrm{~m}^{3}\right)$ of OPC concrete production to the production of the same unit of a BC concrete. For example, Teixeira et al. (2016) used a FU of $1 \mathrm{~m}^{3}$ of concrete to compare between FA and bio mass as supplementary cementitious materials (SCM). Similarly, Park et al. (2012) attempted to correlate the compressive strength of $\mathrm{BC}$ concrete to the environmental impact empirically. Tait and Cheung (2016) also used $1 \mathrm{~m}^{3}$ of concrete as a FU when measuring the environmental impact of concrete containing 35\% FA or $70 \%$ GGBS. The claims made by the above authors justify this selection, and they believe that it is vital to only signify the differences in the emissions and energy during the production 
phase assuming that the remaining phases of the life cycle is similar for both conventional and non-conventional concrete mixes (Tait and Cheung, 2016).

However, the above assumption may not be correct when service life or strength of concrete is considered. For example, Islam and Islam (2013) showed that by replacing OPC with $30 \%$ FA, the compressive strength of concrete decreases up to $30 \%$ at 28 days, but it increases up to $20 \%$ at 365 days. This could be attributed to the chemical composition as well as micro size of the FA particles which enhances its pozzolanic activity potential (Soleymani-Ashtiani et al., 2013). Nath and Sarker (2011) argued that at any replacement ratio, FA-based concrete has higher chloride penetration resistance than OPC concrete. This could be attributed according to the higher chloride binding capacity of the chemical phases available in the denser and more electrically conducting microstructure of FA-based concrete compared to OPC concrete (Soleymani-Ashtiani et al., 2013). According to Gutiérrez et al. (2017), the comparison between the environmental impacts of two construction materials can be reliable, only after considering the combined effects of mechanical and durability characteristics. These factors signify the need to include the use phase of the BC concrete in any LCA study. Hence, simple FU are seen as the least accurate in quantifying the environmental impact of $\mathrm{OPC}$ concrete compared to a $\mathrm{BC}$ concrete one.

\subsection{Complex Functional Unit - Mechanical Properties}

In this FU system, the mechanical properties and environmental impacts are considered as a main factor to optimize concrete. For example, Damineli et al. (2010) considered the influence of the 28 days compressive strength by dividing the amount of binder in a concrete mix relative to the required performance index. One of the issues that emerges from these findings is that they disregards the fact that concrete mixes with the same binder content may have different mechanical properties when superplasticizers or fillers are introduced (Gutierrez et al., 2017). Then, Chiaia et al. (2014) came up with another modified mechanical performance index by considering compressive strength, flexural strength, tensile strength and creep. However, this also focused on 28 days compressive strength when in fact most blended cement concretes achieve their maximum compressive strength after 365 days (Uysal and Akyuncu, 2012). More importantly, these FU focused only on the mechanical properties as a main indication to make the difference between the $\mathrm{BC}$ concrete and OPC concrete performances. Given the scope of this study is reinforced concrete, according to Mahima et al. (2018), premature concrete deterioration, due to carbonation and chloride penetration, is responsible for US\$2.2 trillion, which is equivalent to $3 \%$ of the world's gross domestic product (GDP). This means that durability is a more detrimental factor to the performances of concrete than that of the compressive strength. Thus, durability of concrete is an essential factor that needs to be included when LCA of reinforced BC concrete compare to reinforced OPC concrete.

\subsection{Complex Functional Unit - Durability Parameters}

In this FU system, the environmental impact categories of concrete are directly compared with its durability characteristics without calculating the service life. For example, Panesar et al. (2017) defined a functional unit where the volume of the BC 
concrete is multiplied by its compressive strength and the chloride ion penetration resistance, and compared to the FU of an equivalent OPC concrete. Similarly, Kurda et al. (2018) multiplied the "relative environmental impact of FA concrete compared to that of an OPC concrete" by the "relative chloride penetration coefficient" in order to optimize concrete mixes in terms of durability and environmental impact. Additionally, the same two mentioned parameters were also used by Celik et al. (2015) when comparing durability based environmental impact of conventional concrete with concrete mixes containing both FA and lime.

Celik et al. (2015) and Kurda et al. (2018) used experimental data of the different BC concrete mixes in terms of compressive strength and chloride penetration to compare the performance of $\mathrm{BC}$ concrete with OPC concrete. However, in order to for the absolute environmental impact values to be credible, according to Gutierrez et al. (2017), these durability properties need to be translated into an indicator of the material in use, which is the service life. Although chloride penetration is a very good indicator of durability, but carbonation is more detrimental to the concrete due to two main influences. Firstly, when determining the environmental impact of concrete over its whole service life, the difference in resistance to carbonation could decrease the service life of concrete up to $70 \%$. Secondly, the difference in positive environmental impact by carbon sequestration each SCM concrete has compared to OPC concrete (Collins et al., 2010). In addition, the chloride ion penetration resistance can be considered as an essential factor to define the service life of concrete used in the marine (close to the sea) or underground (foundation) structures, but for other than the mentioned cases, it may not significantly affect the service life of concrete.

\subsection{Complex Functional Unit - Service Life Impacts}

In relative to other FU system (i-iii), this system (environmental impacts versus service life) is the most accurate FU that can be used to optimize conventional and nonconventional concrete mixes in terms of sustainability. For example, Muller et al. (2016) specified as the "sustainability potential" of materials that entails either maximizing the mechanical and durability properties of the material or minimizing its environmental impact up to production stage. Gutierrez et al. (2017) devised a FU that divides the volume of cement by the number of years of durability. Furthermore, an accurate methodology was proposed by Gettu et al. (2018), where the test results for the carbonation, chloride penetration and compressive strength of thirty different BC concrete mixes were incorporated into two FU. In the first FU (Energy intensity) the volume is divided by the compressive strength indicating performance, and in the second FU (A-indices) the carbonation and chloride penetration parameters are converted into expected service life predictions.

However, in all of the aforementioned, concretes with more than a 100 years of durability will have a better environmental impact using both indices, when the structure that this concrete will be used for could only be intended to last 100 years. The same concept could be applied to compressive strength. Not capping the performance nor the durability of the concrete understudy, though maximizes the sustainability potential according to Muller et al. (2016), impinges upon the performance base specifications of concrete. A concept that this study intends to 
highlight is performance based design. As stated by Alexander and Thomas (2015) and Hooton and Bickley (2014), it is the core of concrete sustainability, to design the material fit-to-purpose to the intended use. For example, selecting and proportioning a concrete mix should begin with deciding the performance indicators, such as exposure conditions, mechanical properties and service life, then translate those to the corresponding parameters, which are the compressive strength, the resistance to chloride penetration and to carbonation.

Garcia-Segura et al. (2014) and Heede and de Belie (2010) both accounted 100 years timeframe as the service life of concrete, but only carbonation was used to determine the service life and the compressive strength was left out. Al-Ayish et al. (2018) followed the same accurate methodology by comparing the probabilistically predicted service life based on the chloride penetration resistance of concrete. However, in terms of scope, carbonation was needed to estimate the service life prediction. In terms of methodology, though performance based, mechanical properties were not included in as a performance parameter. Additionally, absolute environmental impact findings are not transferrable to other case studies because they are local to the concrete types and mixes.

\section{PERFORMANCE BASED LCA APPROACH}

The literature findings show no consensus on an accurate and hence indicative LCA FU that accounts for the whole life cycle of a BC reinforced concrete mix and compare it with the corresponding alternatives of OPC concrete or other blended cement concrete. This study presents a novel approach for LCA that helps the user (e.g. structural engineer or architect) in terms of the decision making regarding the type of concrete to be used for any application as well as the mix composition. A performance based approach that meets the required material specifications and generates the resulting environmental impact, which could then be minimized. The purpose of this approach is to be later adopted by advisory boards and experts as a starting point for a standardized approach of quantifying the environmental impact of reinforced BC concrete. In order to understand the novelty of this approach, a standard LCA study is assessed, in which a user is comparing between the environmental impact of several BC concrete mixes and a control OPC concrete mix. According to Muller et al. (2016), an LCA study is divided into four main steps.

\subsection{Goal and Scope Definition}

As established in the literature, for an accurate assessment of the environmental impact, the "use" and "end-of-life" phases (Figure 1) of concrete need to be considered. Unlike all the previous studies, this approach is designed to be prospective, which means that the project is yet to be completed. This allows the user freedom of changing the mixing proportions for a $\mathrm{BC}$ concrete. In addition, there is no barrier for this framework to be used for other Green concrete types (e.g. geopolymer, lime pozzolanic and bioconcrete). 


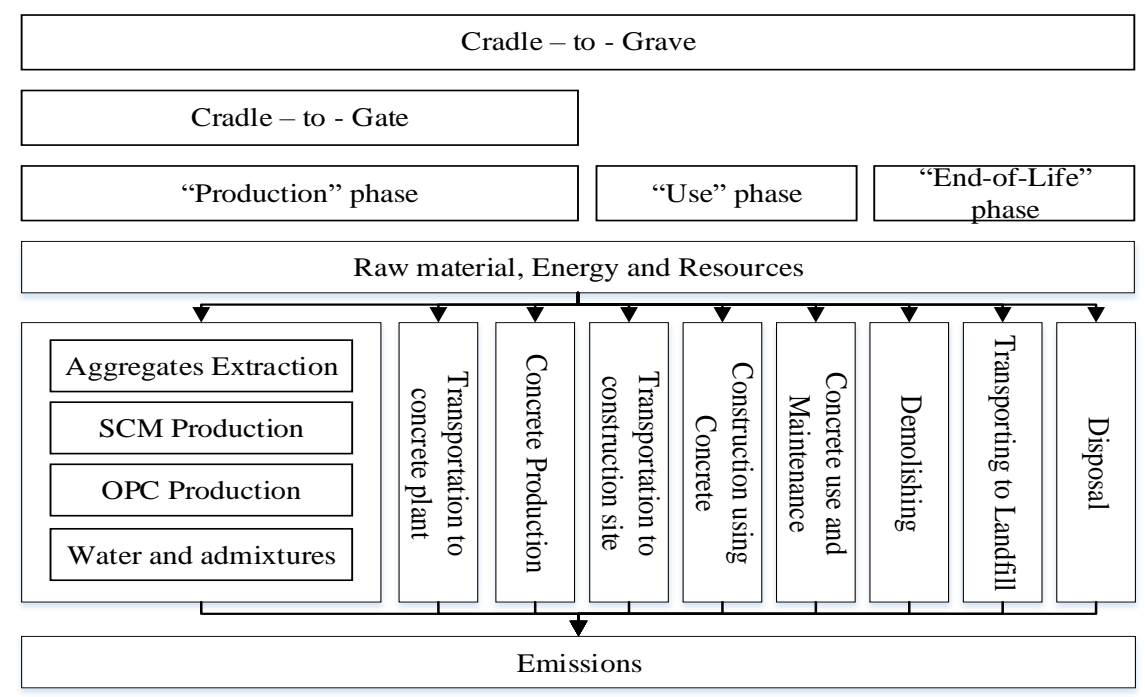

Figure 1: A schematic of the flow chart representing the concrete life cycle phases

After deciding on the scope, the user needs to calculate a FU that includes the burden associated with the "production", "use" and "end-of-life" phases. This will guarantee an accurate estimate across all the studies reinforced BC concretes when assessing their environmental impact.

As seen in the proposed approach in Figure 2, in order to calculate the FU, the user needs to go through the following process ( $a, b, c$ and d). Note that the approach involves system alerts that can be designed and implemented in a tool or software.

a) Specify the project parameters. In this step, the following points need to be decided based on the project:

- The required service life $\left(\mathrm{SL}_{\mathrm{t}}\right)$;

- Targeted compressive strength (CSt);

- Exposure conditions (EC);

- Concrete cover (CC).

b) Specify the mixing proportions of the reinforced BC concrete (green dash line)

c) Using prediction model from the literature, the user inputs data from the previous steps ( $\mathrm{a}$ and $\mathrm{b}$ ) to predict the following parameters.

- Compressive strength $\left(\mathrm{CS}_{\mathrm{p}}\right)$. Unless project specifications state 28-days compressive strength is to be used, it is advised to use a 90-days compressive strength prediction of $\mathrm{BC}$ concrete such as that in Bashkara et al. (2017), to accommodate for the slow strength development due to pozzolanic reactions (Islam and Islam, 2013).

- Service life based on durability against chloride penetration $\left(\mathrm{SLCP}_{\mathrm{p}}\right)$. Based on the selected mixing proportions and the given EC and $\mathrm{CC}$, the "ERFC" model proposed by Al-Ayish et al. (2018) could be used.

- Service life based on durability against carbonation $\left(\mathrm{SLC}_{\mathrm{p}}\right)$. Based on the selected mixing proportions and the given EC and $\mathrm{CC}$, the model used in Garcia-Segura et al. (2014) -for example- could be used. 
- Predicted service life of the BC concrete is then calculated $\left(\mathrm{SL}_{\mathrm{p}}\right)$ as the smaller of $\mathrm{SLCP}_{\mathrm{p}}$ and $\mathrm{SLC}_{\mathrm{p}}$.

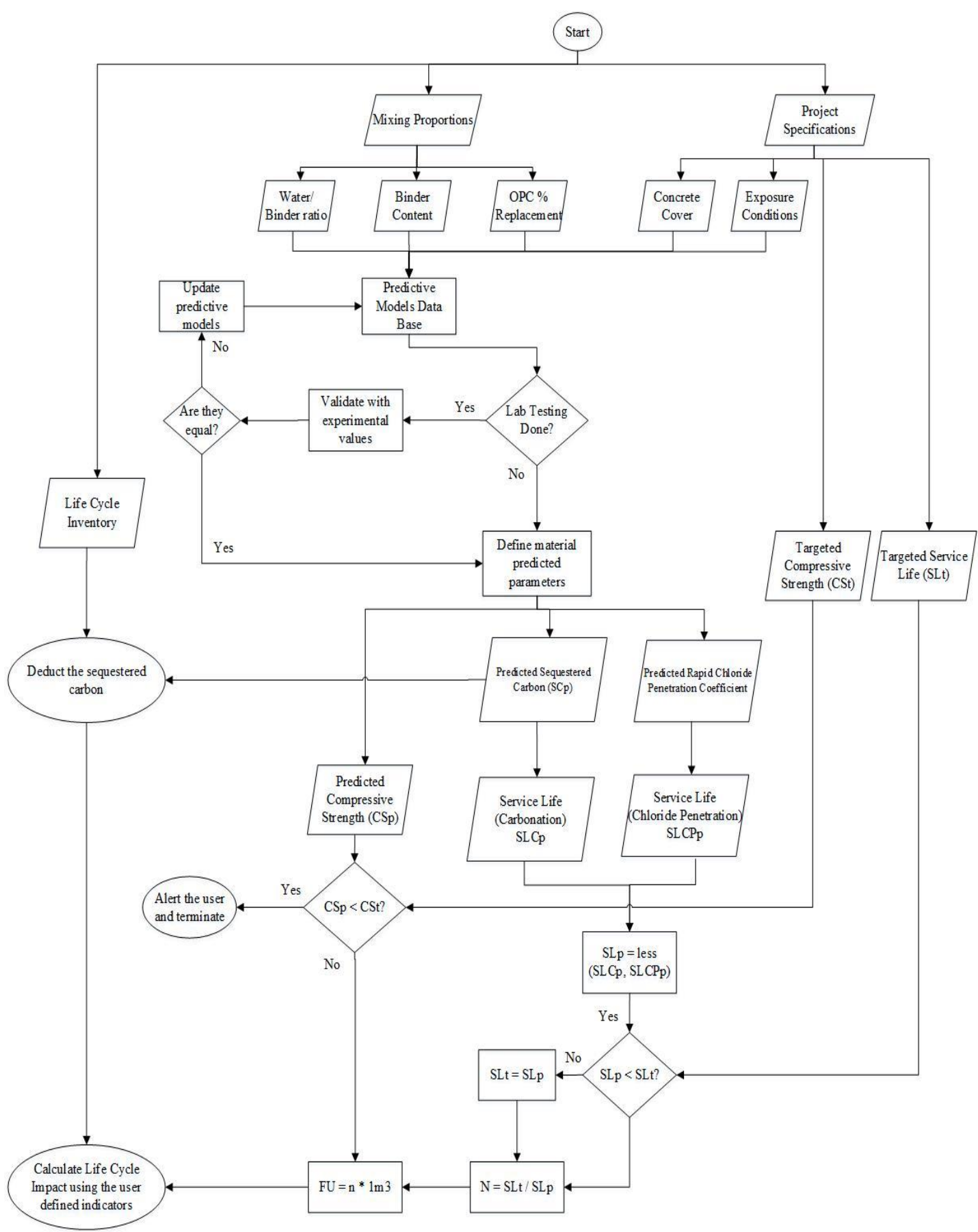

Figure 2 - A Flowchart showing the novel performance based LCA approach

d) If there is an opportunity to validate the regression coefficients of the empirical equations used in the selected prediction models, the user need to perform the required experimental test and determine the performance properties. In case 
the properties predicted contradicts with the tested ones, the values from the experimentation prevail are used to determine the performance parameters. Then, the selected prediction models are updated accordingly.

e) As seen in Figure 2, in order to comply with the performance based principals, the user then compares between the targeted performance parameters $\left(\mathrm{SL}_{\mathrm{t}}, \mathrm{CS}_{\mathrm{t}}\right)$ and the predicted ones $\left(\mathrm{SL}_{\mathrm{p}}, \mathrm{CS}_{\mathrm{p}}\right)$. For example,

- If they are the same $( \pm 10 \%)$, the $\mathrm{FU}=1 \mathrm{~m}^{3}$ of the reinforced concrete. Note that the predicted parameters are probabilistic, so the user needs to decide on a percentage yield. This percentage is directly related to the probability distribution in each of the prediction models used and should match the aspired confidence level of the user.

- If $\mathrm{SL}_{\mathrm{p}}<\mathrm{SL}_{\mathrm{t}}$, the user is alerted that this concrete mix needs to be replaced " $n$ " times to fulfil the project specified service life, where $n=$ $\mathrm{SL}_{\mathrm{t}} / \mathrm{SL}_{\mathrm{p}}$. Hence, an adjustment to the FU occurs to account for this, where: $\mathrm{FU}=\mathrm{n}^{*} 1 \mathrm{~m}^{3}$.

- $\mathrm{SL}_{\mathrm{p}}<\mathrm{SL}_{\mathrm{t}}$, in order to follow the performance based principles; the service life of the concrete's "use" phase is capped at SLt. Hence, the user is alerted and $n=1$.

- If $\mathrm{CS}_{\mathrm{p}}<\mathrm{CS}_{\mathrm{t}}$, the user is alerted and the LCA should be terminated. The reason is that regardless of the environmental impact, this concrete mix does not comply with the minimum required CS in the project. If $\mathrm{CS}_{\mathrm{p}}$ $>\mathrm{CS}_{\mathrm{t}}$, the user is also alerted that this is not an efficient utilization of resources and that a concrete with less CS could be used, but the study continues. Unlike what was done in the service life adjustment, the difference between the $\mathrm{CS}_{\mathrm{p}}$ and $\mathrm{CS}_{\mathrm{t}}$, is not accounted for. The logic here is that, according to Chiaia et al. (2014), compressive strength is directly proportional to the environmental impact. This means that if the user opts to use a mix with $\mathrm{CS}_{\mathrm{p}}>\mathrm{CS}_{\mathrm{t}}$, it will probably result in higher environmental impact.

\subsection{Inventory Analysis}

This step includes collecting the data about the energy consumption and greenhouse gas emissions associated with all the processes in producing the materials. Nothing is changed in the proposed approach of this study to this step of the LCA. However, for the approach to be generic, the inventory data concerning potential SCM considered in the $\mathrm{BC}$ concrete needs to be available. Most of the required data can be usually found in the existing databases of building materials, such as "Ecoinvent" which is associated with the SimaPro software (Gutierrez et al, 2017). If not, the user would then need to search for primary sources (e.g. company specific data, industry data, EPD report and finally site-specific data) concerning the greenhouse gas emissions and energy consumption in the production of the SCM.

\subsection{Life Cycle Impact Assessment}

Nothing changes in this step than a normal LCA. After calculating the FU, the impact assessment is calculated based on the selected indicators. The user need to choose between the mid-point and end-point indicators based on the level of accuracy and depending on the technical knowledge of the user. The calculated impact is then 
reduced to account for the different values for carbon sequestration of each concrete mixes. Carbon sequestration is described as the amount of carbon captured by concrete from the atmosphere as a result from physical and chemical reactions (Garcia-Segura et al., 2014). This process happens throughout the concrete lifecycle as long as concrete is exposed to the atmosphere but is assumed to increase during the end-oflife phase due to the higher surface area exposed then (Wu et al., 2014). Potential of carbon sequestered depends largely on the exposure conditions and the amount of calcium in the binder. Values found in the literature vary between 45\% (Garcia-Segura et al., 2014), 35\% (Xi et al., 2016) and 10\% (Maries et al., 2017).

\subsection{Analysis and Evaluation of Results}

In this final stage of the LCA, the user analyses the calculated environmental impact assessment between the several $\mathrm{BC}$ concrete mixes and chooses the one with the least environmental impact (optimal mixes). The boundary conditions of the LCA would depend on those of the prediction models selected by the user such as the ERFC model that predicts resistance to chloride penetration (Al-Ayish et al., 2018). In this model, the acceptable water/binder ratio ranges between 0.3 and 0.6 , so using increments of 0.1 this will be one of the constraints on the mixing proportions. The accuracy of the results are bound to be affected as well by the accuracy of the model, which is why a probabilistic approach is adopted for these empirical models to educate the user about the accuracy of the results. The user should update them regularly based on: real life sized experiments, laboratory accelerated experiments, field tests from existing structures and experts opinions.

\section{CONCLUSION}

After reviewing the literature, there was no consensus found on the most accurate method to be used to quantify the environmental impact of a blended cement concrete replacing OPC with FA or GGBS. However, an agreement was shown in recent research that the "use" and "end-of-life" phases of concrete need to be included. This is achieved in the novel method proposed in this study building on a performance based approach. Using the model proposed, a user can reach a prospective judgment on the optimum type and mixing proportions of a reinforced blended cement concrete accurately. The approach adjusts the FU of the LCA by comparing the predicted and project specified compressive strength and service life based on chloride penetration and carbonation. Accordingly, the environmental impact is quantified while accounting for performance based project specific parameters. The amount of carbon expected to be sequestered throughout the concrete life cycle is then deducted. It is believed that this method could be widened to assess the environmental impact of other types of sustainable concrete such as alkali activated concrete, lime pozzolans or bioconcrete. The only predecessor for the suitability of the model for use to other concretes would be the availability of established predictive models for the specified performance parameters in the literature. The next step in this research work would be to do a case study comparing the use of this framework as opposed to existing ones from the literature. Finally, an economic comparison between the different concretes under study should be also introduced in the future to this method in order to produce a more holistic judgement to the user. 


\section{REFERENCES}

Al-Ayish, N., During, O., Malaga, K., Silva, N. \& Gudmundsson, K. 2018. The influence of supplementary cementitious materials on climate impact of concrete bridges exposed to chlorides. Construction and Building Materials, 188, 391-398.

Alexander, M. \& Thomas, M. 2015. Service life prediction and performance testing - Current developments and practical applications. Cement and Concrete Research, $78,155-164$.

Celik, K., Meral, C., Petek Gursel, A., Mehta, P. K., Horvath, A. \& Monteiro, P. J. M. 2015. Mechanical properties, durability, and life-cycle assessment of selfconsolidating concrete mixtures made with blended portland cements containing fly ash and limestone powder. Cement and Concrete Composites, 56, 59-72.

Colangelo, F., Forcina, A., Farina, I. \& Petrillo, A. 2018. Life Cycle Assessment (LCA) of different kinds of concrete containing waste for sustainable construction. Buildings, 8.

Collins, F. 2010. Inclusion of carbonation during the life cycle of built and recycled concrete: influence on their carbon footprint. The International Journal of Life Cycle Assessment, 15, 549-556.

Chiaia, B., Fantilli, A. P., Guerini, A., Volpatti, G. \& Zampini, D. 2014. Ecomechanical index for structural concrete. Construction and Building Materials, 67, 386-392.

Damineli, B. L., Kemeid, F. M., Aguiar, P. S. \& John, V. M. 2010. Measuring the ecoefficiency of cement use. Cement and Concrete Composites, 32, 555-562.

De Schepper, M., Van Den Heede, P., Van Driessche, I. \& De Belie, N. 2014. Life cycle assessment of completely recyclable concrete. MATERIALS, 7.

Dobbelaere, G., De Brito, J. \& Evangelista, L. 2016. Definition of an equivalent functional unit for structural concrete incorporating recycled aggregates. Engineering Structures, 122, 196-208.

García-Segura, T., Yepes, V. \& Alcalá, J. 2014. Life cycle greenhouse gas emissions of blended cement concrete including carbonation and durability. international journal of life cycle assessment, 19, 3-12.(Al-Ayish et al., 2018)

Gettu, R., Pillai, R., Santhanam, M., Basavaraj, A., Rathnarajan, S. \& Dhanya, B. 2018. Sustainability-based decision support framework for choosing concrete mixture proportions. Materials and Structures, 51, 1-16.

Hooton, R. D. \& Bickley, J. A. 2014. Design for durability: The key to improving concrete sustainability. Construction and Building Materials, 67, 422-430.

Islam, M. M. \& Islam, M. S. 2013. Strength and Durability Characteristics of Concrete made with Fly-Ash Blended Cement. Australian Journal of Structural Engineering, $14,303-319$. 
Kayali, O. \& Sharfuddin Ahmed, M. 2013. Assessment of high volume replacement fly ash concrete - Concept of performance index. Construction and Building Materials, 39, 71-76.

Knoeri, C., Sanyé-Mengual, E. \& Althaus, H.-J. 2013. Comparative LCA of recycled and conventional concrete for structural applications. The International Journal of Life Cycle Assessment, 18, 909-918.

Kurda, R., Silvestre, J. D. \& De Brito, J. 2018. Life cycle assessment of concrete made with high volume of recycled concrete aggregates and fly ash. Resources, Conservation \& Recycling, 139, 407-417.

Müller, H. S., Haist, M. \& Vogel, M. 2014. Assessment of the sustainability potential of concrete and concrete structures considering their environmental impact, performance and lifetime. Construction and Building Materials, 67, 321-337.

Nath, P. \& Sarker, P. 2011. Effect of Fly Ash on the Durability Properties of High Strength Concrete. Procedia Engineering, 14, 1149-1156.

Panesar, D., Seto, K. \& Churchill, C. 2017. Impact of the selection of functional unit on the life cycle assessment of green concrete. The International Journal of Life Cycle Assessment, 22, 1969-1986.

Park, J., Tae, S. \& Kim, T. 2012. Life cycle CO2 assessment of concrete by compressive strength on construction site in Korea. Renewable and Sustainable Energy Reviews, 16, 2940-2946.

Possan, E., Dal Molin, D. \& Andrade, J. 2018. A conceptual framework for service life prediction of reinforced concrete structures. Journal of Building Pathology and Rehabilitation, 3, 1-11.

Sagastume Gutiérrez, A., Cabello Eras, J. J., Gaviria, C. A., Van Caneghem, J. \& Vandecasteele, C. 2017. Improved selection of the functional unit in environmental impact assessment of cement. 168, 463-473.

Serres, N., Braymand, S. \& Feugeas, F. 2016. Environmental evaluation of concrete made from recycled concrete aggregate implementing life cycle assessment. Journal of Building Engineering, 5, 24-33.

Seto, K. E., Churchill, C. J. \& Panesar, D. K. 2017. Influence of fly ash allocation approaches on the life cycle assessment of cement-based materials. Journal of Cleaner Production, 157, 65-75.

Soleymani Ashtiani, M., Scott, A. N. \& Dhakal, R. P. 2013. Mechanical and fresh properties of high-strength self-compacting concrete containing class $\mathrm{C}$ fly ash. Construction and Building Materials, 47, 1217-1224.

Tait, M. W. \& Cheung, W. M. 2016. A comparative cradle-to-gate life cycle assessment of three concrete mix designs. The International Journal of Life Cycle Assessment 21 (6), 847-860 
Teixeira, E. R., Mateus, R., Camões, A. F., Bragança, L. \& Branco, F. G. 2016. Comparative environmental life-cycle analysis of concretes using biomass and coal fly ashes as partial cement replacement material. Journal of Cleaner Production, 112, 2221-2230.

Uysal, M. \& Akyuncu, V. 2012. Durability performance of concrete incorporating Class F and Class C fly ashes. Construction and Building Materials, 34, 170-178.

Van Den Heede, P. \& De Belie, N. 2010. Durability related functional units for life cycle assessment of high-volume fly ash concrete.

Viñuales, J. E., Depledge, J., Reiner, D. M. \& Lees, E. 2017. Climate policy after the Paris 2015 climate conference. Climate Policy, 17, 1-8.

Wang, S.-D. \& Scrivener, K. L. 1995. Hydration products of alkali activated slag cement. Cement and Concrete Research, 25, 561-571.

Wu, L.-J., Zhou, Y.-J., Kou, X.-J. \& Jiang, M. 2015. Reliability-based service life prediction of existing concrete structures under marine environment. Journal of Central South University, 22, 3608-3614. 